\begin{abstract}
Iranica
Abstracta Iranica Revue bibliographique pour le domaine irano-aryen

Volume 32-33 | 2013

Comptes rendus des publications de 2009-2010
\end{abstract}

\title{
Chuto kenkyu (Etudes du Moyen-Orient). n508, Vol. I
}

Yoko Suzuki

\section{OpenEdition}

1 Journals

\section{Édition électronique}

URL : http://journals.openedition.org/abstractairanica/41020

DOI : 10.4000/abstractairanica.41020

ISSN : 1961-960X

Éditeur:

CNRS (UMR 7528 Mondes iraniens et indiens), Éditions de l'IFRI

\section{Édition imprimée}

Date de publication : 1 décembre 2013

ISSN : 0240-8910

\section{Référence électronique}

Yoko Suzuki, « Chuto kenkyu (Etudes du Moyen-Orient). n508, Vol. I », Abstracta Iranica [En ligne], Volume 32-33 | 2013, document 449, mis en ligne le 01 juillet 2016, consulté le 27 septembre 2020. URL : http://journals.openedition.org/abstractairanica/41020; DOI : https://doi.org/10.4000/ abstractairanica. 41020

Ce document a été généré automatiquement le 27 septembre 2020.

Tous droits réservés 


\title{
Chuto kenkyu (Etudes du Moyen- Orient). n508, Vol. I
}

\author{
Yoko Suzuki
}

\section{RÉFÉRENCE}

Chuto kenkyu (Etudes du Moyen-Orient). Chuto chosakai, 2010/2011, no. 508, vol I, Tokyo, $119 \mathrm{p}$.

1 En 2009-2010, pour garder en mémoire le trentième anniversaire de la révolution islamique et celui du début de la guerre Iraq-Iran, plusieurs revues japonaises ont été spécialement éditées sur la société et la politique de l'Iran et du Golfe persique. Nous verrons ci-dessous les titres de l'une d'elles :

2 Numéro spécial (vol. 1) : traces des changements en Moyen-Orient - 20 ans après la crise du Golfe persique, 30 ans après le déclenchement de la guerre Iraq-Iran (Chuto, henka no kiseki - wangan kiki kara 20nen, iran'iraku senso boppatsu kara 30nen)

3 Kazuo Takahashi, «Ahmadīnežād et Schumpeter » (ahumadinejado to shunpētā)

4 Shuji Hosaka, « Dans un coin de la mémoire - observations sur la place de la crise et la guerre du Golfe persique » (kioku no nagori - wangan kiki to wangan sensou no genba kara)

5 Mariko Mori, «Théorie du Hamās et son projet de paix avec Israël - Transformation pragmatique " (hamāsu no ronri to tai isuraeru wahei - puragumathizumu heno henyou 1987 2007)

6 Dai Yamao, «Les élections du Parlement iraquien (le 7 mars 2010) et la dichotomie politique » (iraku kokkai senkyo (2010nen 3 gatsu 7 ka) to bunkyokuka suru iraku seiji)

7 Yoshitomo Takeuchi, «Souvenir des Japonais pris en otage par le Président Huseyn » (husein-moto daitouryouni shuudan hitojichi ni sareta - nihonjin no tsuioku) 
8 Kazumi Yamazaki, « le peuple séparé - ses collisions au jour de la fête d'Ašrā et à celui de l'anniversaire de la révolution islamique " (bundan sareru iran minshuu - āshūrāto kinen kakumeikinenbi no shoutotsu).

\section{AUTEURS}

\section{YOKO SUZUKI}

Paris 